\title{
High Precision Titrimetry, Ion Chromatography and ICP-Optical Emission Spectrometry for the Estimation of Inhomogeneities in Aqueous Calibration Solutions for Metrological Purposes
}

\author{
Michael Weber*, Jürg Wüthrich, and Sergio Rezzonico \\ Swiss Federal Laboratories for Materials Testing and Research (EMPA), CH-9014 St. Gallen, Switzerland
}

Received June 20, 2003; accepted December 18, 2003; published online March 25, 2004

(C) Springer-Verlag 2004

\begin{abstract}
The homogeneity of samples intended for metrological intercomparison studies must be granted without ambiguity. This holds equally true for aqueous solutions for which the determination of betweenbottle variations requires measurement techniques with extremely high precision. Therefore measurement series were designed for automated analysis techniques such as titrimetry, optical emission spectrometry and ion chromatography which offer very high precision of results. Between-bottle relative standard deviations (RSD) of at best $0.008 \%$ were obtained with titrimetry. With optical emission spectrometry and ion chromatography, between-bottle RSD's of $0.02 \%$ and $0.05 \%$ were obtained. The contributions from these measurements were included in a conservative approach to the uncertainty budgets of the gravimetrical reference values for the analytes in the samples.
\end{abstract}

Key words: Metrology; ion analysis; homogeneity; calibration solution; precision; repeatability; uncertainty.

National metrological institutes (NMIs) compare their measurement results by participating in intercomparison studies at a metrological level, and this data represents the NMI's measurement capability [1, 2]. Since 1999 such intercomparisons were carried out using calibration solutions at the $1 \mathrm{~g} \mathrm{~kg}^{-1}$ level of the cations aluminium,

\footnotetext{
* Author for correspondence. E-mail: michael.weber@empa.ch
}

copper, iron, magnesium and for the anions chloride and phosphate $[3,4]$. The comparability of the NMI's results for such intercomparison studies with calibration solutions was very good, and deviation from the reference value of most results was less than $0.1 \%$ rel. [5]. Therefore it is of particular importance to know the exact value and uncertainty of the mass fraction of the analyte in these intercomparison samples provided by the piloting NMI. In the case of synthetic sample solutions, i.e. calibration solutions, the accuracy of the gravimetric reference value can be granted by using analyte materials of lowest uncertainty of mass fraction of main component on the one hand and performing all weighing operations in a weighing room on the other hand.

There are two types of calculable contributions for the determination of the uncertainty budget of the gravimetric reference value: the uncertainty of the mass value from weighing and the uncertainty of the purity of the reference material. Consideration of these uncertainty contributions only leads to combined uncertainties of the reference value of only $0.002 \%$ rel. $[3,6]$. If the whole production procedure is taken into account, which includes the cleaning-up procedures (if possible), dissolution of the materials in acid or water, dilution, sample handling, homogenization and bottling - and if possible contamination and blanks are considered - an uncertainty budget of $0.002 \%$ is regarded as too optimistic. 
This holds true if all operations are performed under controlled clean room conditions. Many other factors may affect the uncertainty of the analyte value, including inhomogenous dissolution or mixing of the starting material in the batch solution or different behavior of the individual sample solution in the PP bottles (adsorption on bottle surface, evaporation of liquids). Maybe nobody would expect significant inhomogeneities in a $20 \mathrm{~L}$ batch of a $1 \mathrm{~g} \mathrm{~kg}^{-1}$ single element solution after the FEP-coated container is tumbled overhead for 12 hours. Nevertheless, homogeneity of the analyte in the bottled samples is assumed but has not been established experimentally. As it is one of the main aims of the metrological community to elucidate unsolved questions and determine uncertainties from influence parameters, we decided to develop a novel approach to the conservative determination of betweenbottle inhomogeneities of aqueous samples.

It goes without saying that only highly automated techniques with very low levels of uncertainty were considered. Therefore we compared the results from titrimetry, ion chromatography and ICP optical emission spectrometry in terms of best achievable repeatability. When assuming that within-bottle inhomogeneity in the $250 \mathrm{~mL}$ bottles is negligible (after shaking them very well), the between-bottle variability of the results as the relative standard deviation (RSD) of the mean values of all bottles can be taken as a rough and conservative estimation of the supposed betweenbottle inhomogeneity. Because the repeatability of the measurement technique is included in this estimation, this approach represents a worst case scenario.

\section{Experimental}

\section{Apparatus}

Titrations were performed under argon atmosphere on a modular automatic system from Metrohm (Herisau, Switzerland) with a 730 sample changer with 2 working stations, a 662 Photometer including a glass fiber light guide with a mirror with a $2 \times 10=20 \mathrm{~mm}$ light path; wavelength range 400 to $700 \mathrm{~nm}$, dispensing unit 700 Dosino with 796 Titroprocessor, 722 propeller rod stirrer, titration software Metrodata "TiNet ${ }^{\mathrm{C}} 2.4$ " and thermostat with heating finger. For end point detection of copper measurements, an ion selective electrode (Cu-ISE, Metrohm, no. 6.0502.140) with $\mathrm{Ag} / \mathrm{AgCl}$ double junction reference electrode (Metrohm, no. 6.0726.100) was used. For magnesium and chloride titrations, end point detections were performed with an $\mathrm{Ag}$ rod electrode (Ag-Titrode, Metrohm, no. 6.0430.100) and Ag/ AgCl double junction reference electrode (Metrohm, no. 6.0726.100).

Inductively coupled plasma optical emission spectrometry (ICPOES) data was measured on a radial-view Optima 3000 instrument (PerkinElmer) with auto sampler AS-90, $40 \mathrm{MHz}$ RF generator, optical system with Echelle polychromator, segmented-array charge-coupled device detector (SCD) and a concentric glass nebuliser Conikal (Glass Expansion SARL, Switzerland). Ion chromatography measurements were performed on an IC system from Metrohm with chemical suppression and conductivity detection consisting of the modules 762 IC Interface, 733 IC Separation Center, 709 IC Pump (double piston pump), 752 IC Pump Unit, 766 IC Sample Processor (injection loop $20 \mu \mathrm{L}$ ), and 732 IC Detector. The anions were separated on a METROSEP A SUPP 5 column $\left(4.0 \times 150 \mathrm{~mm}\right.$, Metrohm) with a $\mathrm{CO}_{3}{ }^{2-} / \mathrm{HCO}_{3}{ }^{-}$eluent $(3.2 \mathrm{mM}$ $\mathrm{Na}_{2} \mathrm{CO}_{3} / 1.0 \mathrm{mM} \mathrm{NaHCO}$, flow $0.7 \mathrm{~mL} \mathrm{~min}^{-1}$ ).

\section{Reagents}

All aqueous solutions were prepared with helium and subsequently ultrasonic bath degassed water (18 MOhm, $0.2 \mu \mathrm{m}$ filtered). The following solutions were prepared using reagents of the highest quality available (analytical or high-purity grade) from Fluka $\mathrm{GmbH}$, Buchs (Switzerand) or Merck AG, Dietikon (Switzerland): 0.01 M $\mathrm{Na}_{2}$ EDTA (from disodium dihydrate salt of the compound), $0.01 \mathrm{M}$ zinc sulfate (from $0.1 \mathrm{M}$ Titrisol ${ }^{\circledR}$ solution), Chromazurol S indicator solution (from $50 \mathrm{mg}$ Chromazurol S in $100 \mathrm{~mL}$ of water), Dithizon indicator solution (freshly prepared from $125 \mathrm{mg}$ Dithizon in $250 \mathrm{~mL}$ of ethanol), $0.0004 \mathrm{M}$ silver nitrate solution (from $1 \mathrm{~mL}$ of a $0.1 \mathrm{M}$ silver nitrate solution in $250 \mathrm{~mL}$ of $0.01 \mathrm{M}$ nitric acid, protected from light), $0.1 \mathrm{M}$ borate buffer solution (from disodium tetraborate in water), acetate buffer solution with $\mathrm{pH} 4.66$ (prepared by mixing the same volumes of $2 \mathrm{M}$ sodium acetate solution and $2 \mathrm{M}$ acetic acid), $2 \mathrm{M}$ ammonia buffer solution (prepared by dissolving $80.0 \mathrm{~g}$ ammonia nitrate and $75 \mathrm{~mL}$ ammonia solution (25\%) in $1000 \mathrm{~mL}$ water).

$1000 \mathrm{mg} \mathrm{kg}^{-1}$ phosphate reference solution (gravimetrically prepared by dissolving $374 \mathrm{mg}$ di-sodium hydrogenphosphate in water to a total of $250 \mathrm{~g}$ solution) and $2000 \mathrm{mg} \mathrm{kg}^{-1}$ sulfate internal standard solution (gravimetrically prepared by dissolving $740 \mathrm{mg}$ sodium sulfate in water to a total of $250 \mathrm{~g}$ of solution).

\section{Procedures}

\section{General Procedure for Titration}

A lot of 8 out of 50 samples was investigated (regular sampling) in all cases. Each of the eight samples $\mathrm{S}_{\mathrm{i}}$ was titrated 10 times under controlled climatic conditions $(50 \% \pm 2 \%$ relative humidity, $23.0^{\circ} \mathrm{C} \pm 0.5^{\circ} \mathrm{C}$ ) giving the following measurement sequence (sample $\mathrm{S}_{\mathrm{i}}$ with $\mathrm{i}=1$ to 8 , replicate number in parentheses): $\mathrm{S}_{1}(1)$, $S_{1}(2), \ldots, S_{1}(10), \ldots, S_{8}(1), \ldots, S_{8}(10)$. Due to the fact that under these conditions drift effects are negligible, the measurement sequence for titrimetry is less important than in the case of ICPOES and IC measurements.

Titration of Iron(III) Solution (1000 $\mathrm{mg} \mathrm{kg}^{-1}$ ) [7]

A mixture of $4.75 \mathrm{~mL}$ iron(III) sample solution in $80 \mathrm{~mL}$ of water was treated with $1 \mathrm{~mL}$ Chromazurol $\mathrm{S}$ indicator solution. After heating to $50^{\circ} \mathrm{C}$, titrations were performed at a $\mathrm{pH}$ of $2-3$ with a $0.01 \mathrm{M} \mathrm{Na}_{2}$-EDTA solution followed by photometric detection at $615 \mathrm{~nm}$ and end point determination by intersection of tangents on titration curve.

Titration of Aluminum(III) Solution $\left(1000 \mathrm{mg} \mathrm{kg}^{-1}\right)[8,9]$

A mixture of $2.00 \mathrm{~mL}$ of aluminum(III) sample solution in $40 \mathrm{~mL}$ of ethanol, $15 \mathrm{~mL}$ of water, $10 \mathrm{~mL}$ acetate buffer and $1 \mathrm{~mL}$ Dithizon 
indicator solution was treated with $18 \mathrm{~mL}$ excess of $0.01 \mathrm{M} \mathrm{Na}_{2}-$ EDTA solution. After heating to $50^{\circ} \mathrm{C}$, back titration with a $0.01 \mathrm{M}$ zinc sulfate solution was performed at $\mathrm{pH} 2-3$ (photometric detection at $515 \mathrm{~nm}$ and tangent intersection method for end point calculation).

Titration of Copper(II) Solution (1000 $\mathrm{mg} \mathrm{kg}^{-1}$ ) [10]

A mixture of $4.75 \mathrm{~mL}$ copper(II) solution in $60 \mathrm{~mL}$ water, $10 \mathrm{~mL}$ acetate buffer solution and $2 \mathrm{~mL}$ of a $1 \mathrm{M}$ sodium hydroxide solution was titrated at $\mathrm{pH} 9.0 \pm 0.5$ with a $0.01 \mathrm{M} \mathrm{Na}_{2}$-EDTA solution. Potentiometric end point indication was applied.

Titration of Magnesium Solution (1000 $\mathrm{mg} \mathrm{kg}^{-1}$ ) [11]

A mixture of $4.00 \mathrm{~mL}$ magnesium sample solution in $20 \mathrm{~mL}$ water, $0.1 \mathrm{~mL} 0.0004 \mathrm{M}$ silver nitrate solution and $40 \mathrm{~mL}$ of $0.1 \mathrm{M}$ borate buffer was titrated at $\mathrm{pH} 9.0-9.2$ with a $0.01 \mathrm{M} \mathrm{Na}_{2}$-EDTA solution. Potentiometric end point indication was applied.

Titration of Chloride Solution (1000 $\mathrm{mg} \mathrm{kg}^{-1}$ )

A mixture of $3.0 \mathrm{~g}$ chloride sample solution in $30 \mathrm{~mL}$ water and $30 \mathrm{~mL}$ acetone was titrated with a $0.005 \mathrm{M}$ silver nitrate solution. Potentiometric end point indication was applied.

Experimental Design of Phosphorus

Determination with ICP OES

A lot of 5 out of a total of 30 produced samples (regular sampling) was investigated. To minimize drift effects in signal intensity during the measurement series, the internal standard (IS) technique with sulfur (as sulfate) as the IS was applied, and the ratio of the $\mathrm{P}$ and $\mathrm{S}$ signals was recorded. The instrument was preconditioned for a minimum of 12 hours (see Results and Discussion). Drift correction was made by measuring a reference solution before and after each sample solution. Sample and reference solutions were prepared with almost similar concentrations $(<1 \%$ rel. difference) and identical matrices (same stoichiometry of materials).

ICP OES Determination of Phosphate

Solution $\left(1000 \mathrm{mg} \mathrm{kg}^{-1}\right)$

The operating conditions are listed in Table $1.6 \mathrm{~g}$ of sulfur IS solution were gravimetrically added to $6 \mathrm{~g}$ from each of the 5 sample solutions and filled up to $50 \mathrm{~g}$ with water in a polypropylene vial. Each sample solution $\mathrm{S}_{\mathrm{i}}$ was divided into 2 sub-samples $\left(\mathrm{S}_{\mathrm{i}} \mathrm{A}\right.$ and
$\mathrm{S}_{\mathrm{i}} \mathrm{B}$ ) and measured between two reference solutions in one set. This set of 20 measurements in total was repeated 7 times so that 14 individual values for each sample solution were obtained. This leads to the following schematic measurement sequence (sample $S_{\mathrm{i}}$ with $\mathrm{i}=1$ to $5, \mathrm{R}=$ reference, replicate number in parentheses): $\mathrm{S}_{1} \mathrm{~A}(1)$, $R, S_{1} B(1), R, S_{2} A(1), R, S_{2} B(1), \ldots, S_{5} B(1), \ldots, S_{1} A(7), R$, $\mathrm{S}_{1} \mathrm{~B}(7), \ldots, \mathrm{S}_{5} \mathrm{~B}(7)$.

\section{IC Analysis of Chloride Solution (1000 $\mathrm{mg} \mathrm{kg}^{-1}$ )}

A lot of 5 out of a total of 30 produced samples (regular sampling) was investigated under controlled climatic conditions $(50 \% \pm 2 \%$ relative humidity, $23.0^{\circ} \mathrm{C} \pm 0.5^{\circ} \mathrm{C}$ ). $10.0 \mathrm{~g}$ of sample solution and $10.0 \mathrm{~g}$ of sulfate IS solution $\left(1600 \mathrm{mg} \mathrm{kg}^{-1}\right)$ were gravimetrically mixed. Each of the 5 sample solutions $S_{\mathrm{i}}$ was divided into two subsamples $\left(\mathrm{S}_{\mathrm{i}} \mathrm{A}\right.$ and $\left.\mathrm{S}_{\mathrm{i}} \mathrm{B}\right)$, and the set of 10 sub-samples was measured 7 times giving 14 results for each of the 5 sample solutions. The "response factors" were recorded (product of chloride signal and chloride sub-sample mass divided by the product of sulfate signal and sulfate sub-sample mass) as results. This leads to the following schematic measurement sequence (sample $S_{i}$ with $i=1$ to 5 , replicate number in parentheses): $\mathrm{S}_{1} \mathrm{~A}(1), \mathrm{S}_{1} \mathrm{~B}(1), \mathrm{S}_{2} \mathrm{~A}(1), \mathrm{S}_{2} \mathrm{~B}(1), \ldots$, $\mathrm{S}_{5} \mathrm{~B}(1), \mathrm{S}_{1} \mathrm{~A}(7), \mathrm{S}_{1} \mathrm{~B}(7), \ldots, \mathrm{S}_{5} \mathrm{~B}(7)$.

\section{Results and Discussion}

\section{Preconditioning and Equilibration of Instruments}

To obtain best repeatabilities it was necessary to bring all the instruments into equilibration while performing a series of pre-measurements. In the case of titrimetry, a test series with 5 measurements led to adequate repeatability, and no significant drift at the level of $<0.01 \%$ RSD was observed during this conditioning time. With the IC instrument, about 10 to 15 pre-measurements were necessary until the signals showed acceptable repeatability due to conditioning of the column. Both the titrimetry and IC apparatuses were located in a climatized laboratory, and only as little changes in temperature as possible were allowed during the measurement series. Switching off the lights or

Table 1. ICP-OES operating conditions for high precision determination of phosphorus

\begin{tabular}{llll}
\hline ICP Source operating parameters & & Spectrometer operating parameters & \\
\hline Plasma flow Ar & $15 \mathrm{~L} \mathrm{~min}^{-1}$ & Signal measurement mode & peak integration, \\
Auxiliary flow $\mathrm{Ar}$ & $0.5 \mathrm{~L} \mathrm{~min}^{-1}$ & & low-res. readout \\
Nebuliser flow Ar & $0.8 \mathrm{~L} \mathrm{~min}^{-1}$ & Background correction & manually selected, \\
Sample uptake rate & $1.5 \mathrm{~mL} \mathrm{~min}^{-1}$ & Measurement time & 2 -point interpolation \\
RF-power & $1300 \mathrm{~W}$ & Integration time & $10 \mathrm{~s}$ \\
Probe rinse & $90 \mathrm{~s}$ & Read delay time & 0.05 \\
& & Replicate measurement & $120 \mathrm{~s}$ \\
& Wavelength analyte & 10 \\
& Wavelength internal standard & $\mathrm{P}$ at $213.618 \mathrm{~nm}$ \\
& & & $\mathrm{~S}$ at $180.669 \mathrm{~nm}$ \\
\hline
\end{tabular}


activating the sleep mode of the monitors during the measurements led to small changes in the room temperature, resulting in a significant effect on the end point detection of the titration curves.

The precision determination of phosphorus measurement in the phosphate solution with ICP-OES proved to be more difficult. In contrast to the prevalently used internal standards, such as manganese or scandium [12], sulfur was chosen (as sulfate salt) in this experiment to be the IS having the development of a high performance OES analysis technique for sulfur determination with phosphorus as internal standard in mind.

Figure 1 shows the response factors of the first measurement series after switching on the instrument. A nonlinear drift of about $40 \%$ increase was observed during a time period of 12 hours. A closer look at the signal intensities of $\mathrm{S}$ and $\mathrm{P}$ revealed that only the signals of $\mathrm{S}$ are responsible for this effect (Fig. 2). It is assumed that traces of oxygen in the optical path of the spectrometer may be the reason for this drift because molecular oxygen absorbs UV light below $200 \mathrm{~nm}$ where the wavelength of the sulfur spectral line used is located. Therefore, with this experimental setup and sulfur as the internal standard, this drift becomes less significant and almost linear only after a purging and operating time of more than 12 hours, enabling the high precision measurement series to be started. A more favorable IS would allow reducing the stabilization time and at the same time similar or bet-

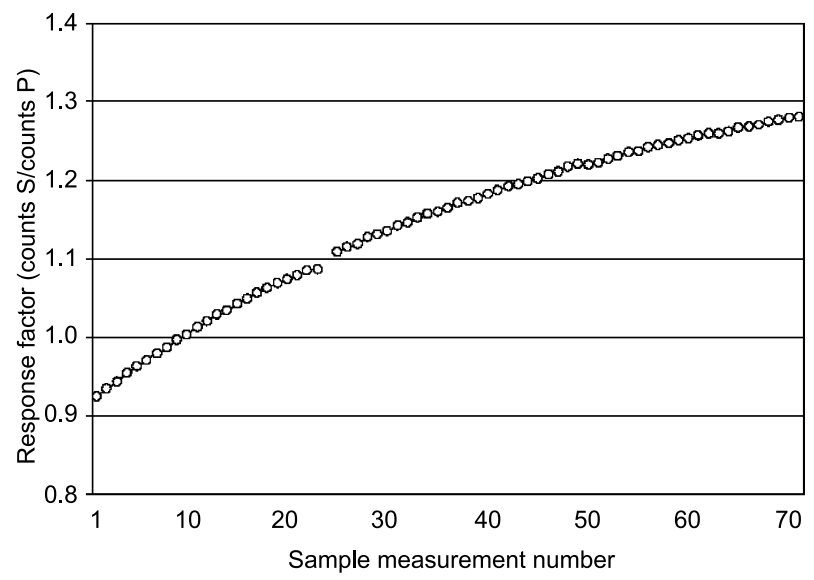

Fig. 1. Intensity ratio of spectral line intensities of sulfur to phosphorous ("response factors") of all 70 phosphate sample measurements after switching on the instrument (reference measurements omitted) showing an increase drift of about $40 \%$ with a tendency to slowly decrease (No. 24 is ignored due to instrument failure)

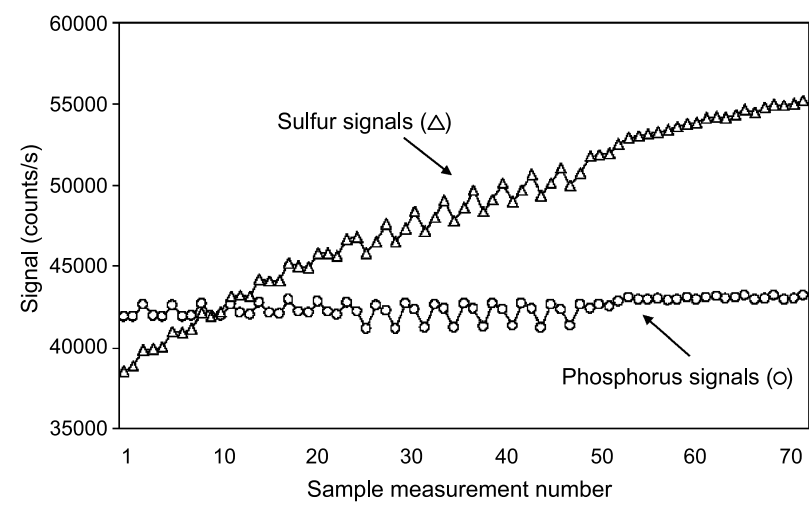

Fig. 2. Highly significant drift in the signals of sulfur used as internal standard led to a nonlinear $40 \%$ drift in the phosphorus measurement series

ter precision are achievable for phosphorus solutions [12]. Nevertheless, it could be demonstrated that sulfur is an adequate IS when the instrument is properly conditioned.

\section{Precision Measurement Series Results}

Table 2 shows the measured RSD results obtained in this repeatability study of the ion calibration solutions investigated. Graphical presentations of all data are given in Fig. 3 (cation solutions) and Fig. 4 (anion solutions). Assuming that inhomogeneity within the $250 \mathrm{~mL}$ samples is negligible, the average withinbottle RSD is defined as $\mathrm{s}_{\text {meas }}$ representing the relative measurement precision. The experimental relative variability between bottles $\mathrm{s}_{\mathrm{bb}}$ is expressed as RSD of the individual within-bottle mean values. Therefore $\mathrm{s}_{\mathrm{bb}}$ represents the RSD of the sample and not the RSD of the sample mean. With regard to measurement precision, titrimetry led to the best results with $\mathrm{s}_{\text {meas }}$ for the copper solution of $0.004 \%$. As expected, the within-bottle RSD $s_{\text {meas }}$ of IC measurements are found to be less precise by almost up to two orders of magnitude compared to titrimetry measurements (Table 2). The differences between IC and titrimetry measurements are less distinctive when looking at the between-bottle RSD $s_{b b}$. Values for $s_{b b}$ from $0.008 \%$ to $0.0038 \%$ are found for titrimetry measurement, whereas the IC measurements lead to $\mathrm{s}_{\mathrm{bb}}$ of $0.053 \%$. This is the consequence of the fact that $\mathrm{s}_{\text {meas }}$ is not included in $\mathrm{s}_{\mathrm{bb}}$.

Making a statement about whether or not there are significant between-bottle inhomogeneities requires a closer look at the ratio of $s_{b b} /\left(s_{\text {meas }} / \sqrt{n}\right)$ whereby $n$ is 
Table 2. Summary of all precision measurements including estimates for uncertainty contribution assumed to be due to between-sample inhomogeneity $\left(* \mathrm{u}_{\text {inhom }}=\mathrm{s}_{\mathrm{bb}}, \mathrm{u}_{\text {inhom }}=\mathrm{s}_{\text {meas }} / \sqrt{\mathrm{n}}\right)$

\begin{tabular}{llllllll}
\hline Analyte & Technique & $\mathrm{n}$ & $\begin{array}{l}\mathrm{s}_{\mathrm{bb}} \\
\%\end{array}$ & $\begin{array}{l}\mathrm{s}_{\text {meas }} \\
\%\end{array}$ & $\begin{array}{l}\mathrm{s}_{\text {meas }} / \sqrt{\mathrm{n}} \\
\%\end{array}$ & $\begin{array}{c}\mathrm{s}_{\mathrm{bb}} /\left(\mathrm{s}_{\text {meas }} / \sqrt{\mathrm{n}}\right) \\
\mathrm{u}_{\text {inhom }} \\
\%\end{array}$ \\
\hline Aluminium & Titration & 10 & 0.025 & 0.036 & 0.011 & 2.2 & $0.025^{*}$ \\
Copper & Titration & 10 & 0.008 & 0.004 & 0.001 & 5.4 & $0.008^{*}$ \\
Iron & Titration & 10 & 0.038 & 0.049 & 0.015 & 2.4 & $0.038^{*}$ \\
Magnesium & Titration & 10 & 0.019 & 0.016 & 0.005 & 3.7 & $0.019^{*}$ \\
Chloride & Titration & 10 & 0.017 & 0.053 & 0.017 & $0.017^{* *}$ \\
Chloride & IC & 14 & 0.053 & 0.345 & 0.092 & 0.6 & $0.092^{* *}$ \\
Phosphate & ICP-OES & 14 & 0.020 & 0.088 & 0.024 & 0.8 & $0.024^{* *}$ \\
\hline
\end{tabular}
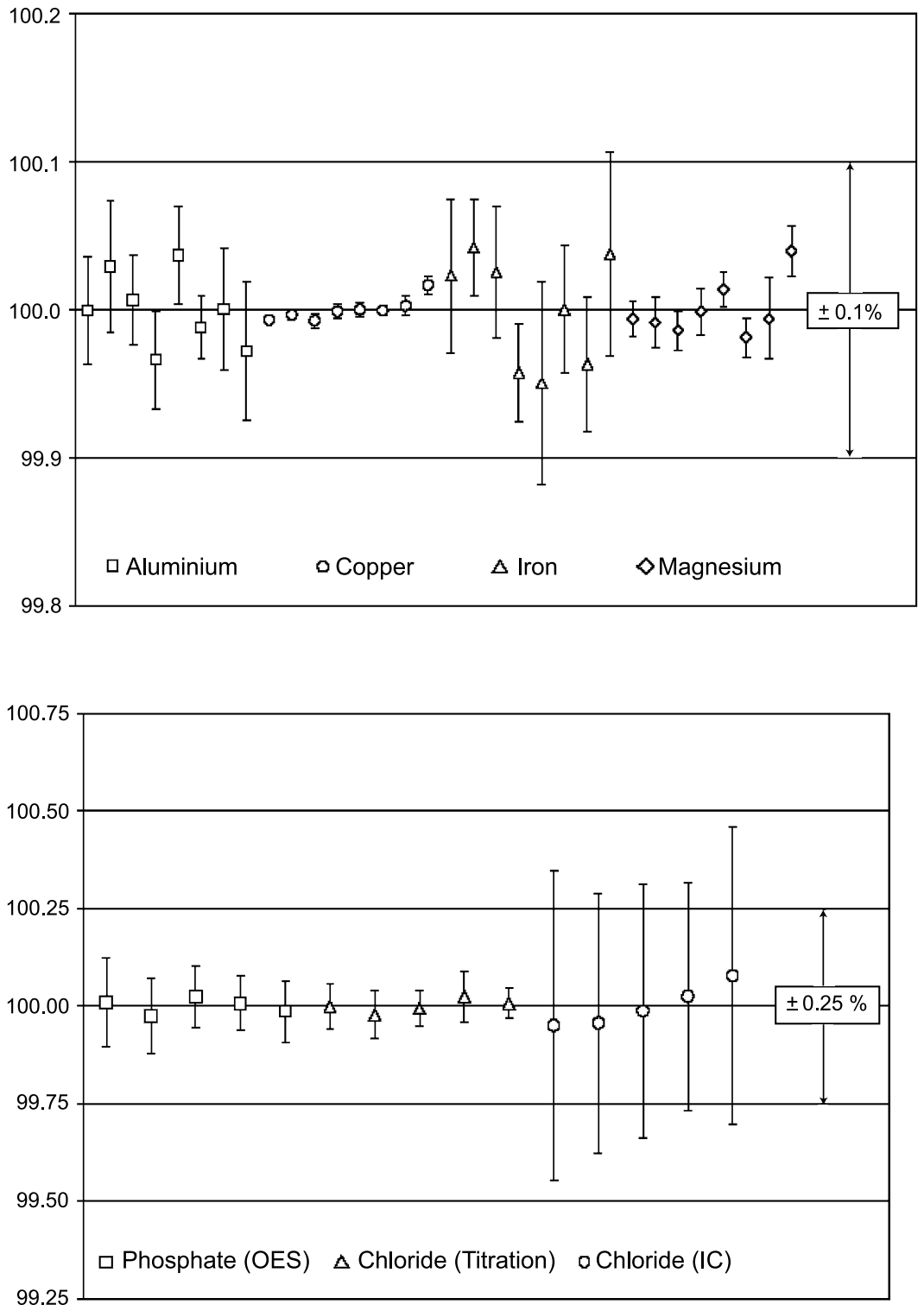

Fig. 3. Results (normalized to 100) from repeatability titrimetry measurements of aqueous $1 \mathrm{~g} \mathrm{~kg}^{-1}$ cation calibration solutions showing between bottle variations of $0.008 \%$ for copper to $0.38 \%$ for iron (the bars illustrate the individual $\mathrm{s}_{\mathrm{i} \text {,meas }}$ for bottle $\mathrm{i}$ )
Fig. 4. Results (normalized to 100) from repeatability measurements of aqueous $1 \mathrm{~g} \mathrm{~kg}^{-1}$ anion calibration solutions with different analysis techniques (cf. Fig. 3) the number of independent replicates per sample. The term $\sqrt{\mathrm{n}}$ takes into consideration that the RSD of the mean is smaller than the RSD of the individual mea- surements following ISO 35. Because the reduction of $\mathrm{s}_{\text {meas }}$ by $\sqrt{\mathrm{n}}$ is only allowed for independent measurements, the replicates should be considered indepen- 
dent if they show no trend or pattern [13]. This is the case for all of the measurement series in this study, as can be seen in Figs. 3 and 4, except for the IC measurement series of chloride solution where a slight tendency of increased values is obtained (see Fig. 4). Due to the IC measurement sequence described in the experimental section, an instrumental drift can not be the reason for this trend because the withinbottle data was not acquired time-correlated. Moreover, a real trend of detected inhomogeneity among the chloride samples may also be unlikely due to the fact that the titrimetry data which is much more significant does not show any trend for the same samples.

If the ratio $s_{b b} /\left(s_{\text {meas }} / \sqrt{n}\right)$ gives a value $>1$, then the between-bottle variation $\mathrm{s}_{\mathrm{bb}}$ is a good but conservative estimate for between-bottle inhomogeneity. When $\mathrm{s}_{\mathrm{bb}}=\mathrm{u}_{\mathrm{inhom}}$, in this case $\mathrm{u}_{\mathrm{inhom}}$ is independent of the number of replicates $\mathrm{n}$. In this study this is only true for the titrimetry measurement series of the four cation solutions leading to the values for $\mathrm{u}_{\text {inhom }}$ given in Table 2. Splitting up $\mathrm{s}_{\mathrm{bb}}$ into a term consisting of $\mathrm{s}_{\text {meas }}$ and the term describing effective between-bottle variability caused by inhomogeneity $s_{\text {inhom }}=u_{\text {inhom }}$ is a less conservative approach to the estimation of $\mathrm{u}_{\text {inhom }}$ in accordance to the GUM [14]. With this approach it is assumed that a measured between-bottle variation $\mathrm{s}_{\mathrm{bb}}$ always contains contributions from the measurement itself:

$$
\mathrm{s}_{\mathrm{bb}}^{2}=\mathrm{u}_{\text {inhom }}^{2}+\frac{\mathrm{s}_{\text {meas }}^{2}}{\mathrm{n}}
$$

which implies

$$
\mathrm{u}_{\mathrm{inhom}}=\sqrt{\left(\mathrm{s}_{\mathrm{bb}}^{2}-\frac{\mathrm{s}_{\mathrm{meas}}^{2}}{\mathrm{n}}\right)}
$$

If we calculate $u_{\text {inhom }}$ following Eq. (2) for the four titrimetry results of the cation solutions where $\mathrm{s}_{\mathrm{bb}} /\left(\mathrm{s}_{\text {meas }} / \sqrt{\mathrm{n}}\right)>1$, this leads to slightly decreased values for $u_{\text {inhom }}\left(u_{\text {inhom }}=0.022 \%\right.$ for $\mathrm{Al}, 0.008 \%$ for $\mathrm{Cu}, 0.035 \%$ for $\mathrm{Fe}, 0.018 \%$ for $\mathrm{Mg}$ solutions). A disadvantage of this approach is that when the values of $s_{b b}$ and $\left(s_{\text {meas }} / \sqrt{n}\right)$ are almost equal, the values for $\mathrm{u}_{\text {inhom }}$ become very small, implying that the approach tends to towards optimistic estimates for the betweenbottle inhomogeneity. In other words, the discriminatory power of this statistical test depends on the precision of the analytical measurements $s_{\text {meas }}$.

Hence, for data sets with a ratio of $\mathrm{s}_{\mathrm{bb}} /\left(\mathrm{s}_{\text {meas }}\right)$ $\sqrt{\mathrm{n}})<1$, no statistically significant statement can be made about $\mathrm{s}_{\mathrm{bb}}$ in terms of inhomogeneity. In this study this is the case for the IC, ICP-OES and chloride titration measurement series. In such cases it is recommended that $\mathrm{u}_{\text {inhom }}$ is set to $\mathrm{u}_{\text {inhom }}=s_{\text {meas }} / \sqrt{\mathrm{n}}$, leading to the values given in Table 2 which are labeled with a double asterisk [15-18]. In these cases $\mathrm{u}_{\text {inhom }}$ is dependent on $\mathrm{n}$. Note that in [15-18] a different notation for $s_{b b}$ and $u_{i n h o m}$ is used.

With the exception of the IC data, all estimates of relative values of $u_{\text {inhom }}$ in this study were in the range of $0.008 \%$ (copper titration) and $0.038 \%$ (iron titration). For the IC series with $\mathrm{u}_{\text {inhom }}=0.092 \%$ it would be possible to decrease the measurement variability by increasing of the number of replicates. However, more than 40 measurement replicates per sample would be necessary to bring the term $s_{\text {meas }} / \sqrt{\mathrm{n}}$ to an equal value as the one for $\mathrm{s}_{\mathrm{bb}}$ $(0.053 \%$ in this case). Nevertheless, it has been demonstrated that when using IC it is possible to detect between-sample inhomogeneities in aqueous solution in the range of $0.1 \%$.

Acknowledgements. The authors are grateful to K. Kehl and M. Val, EMPA St. Gallen (Switzerland). Special thanks to Marc Salit from NIST (US) for kindly introducing us to high performance ICP-OES analysis.

\section{References}

[1] Bureau International des Poids et Mesures (1999) Mutual recognition of national measurement standards and of calibration and measurement certificates issued by national metrological institutes. Paris

[2] Wielgosz R I (2002) Anal Bioanal Chem 374: 767-771

[3] Felber H, Weber M, Rivier C (2002) Metrologia 39 Tech [Suppl] 080022

[4] Weber M, Wüthrich J (2003) Metrologia (submitted for publication)

[5] Weber M, Felber H (2004) Microchimica Acta 146: 91-95

[6] International Recommendation OIML R 111 (1994) Organisation Internationale de Métrologie Légale. Paris

[7] Schwarzenbach G, Flaschka H (1965) Die komplexometrische Titration. Ferdinand Enke Verlag, Stuttgart, p 191

[8] Schwarzenbach G, Flaschka H (1965) Die komplexometrische Titration. Ferdinand Enke Verlag, Stuttgart, p 154, p 159

[9] Wänninen E, Ringbom A (1955) Anal Chim Acta 12: 308

[10] Schwarzenbach G, Flaschka H (1965) Die komplexometrische Titration. Ferdinand Enke Verlag, Stuttgart, p 200

[11] Serjeant E P (1984) Potentiometry and potentiometric titrations. John Wiley \& Sons, New York, p 269

[12] Salit M L, Turk G C, Lindstrom A P, Butler T A, Beck C M II, Norman B (2001) Anal Chem 73: 4821-4829

[13] Certification of reference materials - General and statistical principles (1989) ISO Guide 35

[14] International Standards Organization (1993) Guide to the Expression of Uncertainty in Measurement. Geneva 
[15] Ellison S L R, Burke S, Walker R F, Heydorn K, Månsson M, Pauwels J, Wegscheider W, te Nijenhuis B (2001) Accred Qual Assur 6: 274-277

[16] van der Veen A, Linsinger T, Pauwels J (2001) Accred Qual Assur 6: 26-30
[17] Pauwels J, Lamberty A, Schimmel H (1998) Accred Qual Assur 3: 51-55

[18] Linsinger T, Pauwels J, Heinz Schimmel, Lamberty A, van der Veen A, Schumann G, Siekmann L (2000) Fresen J Anal Chem 368: 589-594 